\title{
Las exploraciones botánicas en el Boletín de la Academia Nacional de Ciencias, Córdoba, Argentina (1874-1887)
}

\author{
Rodrigo Antonio Vega y Ortega Baez**
}

Recibido el 30 de enero de 2019; aceptado el 25 de abril de 2019

\section{RESUMEN}

El objetivo de la investigación es describir el desarrollo de las exploraciones botánicas organizadas por la Academia Nacional de Ciencias en el período 1874-1887 a través del Boletín de la Academia Nacional de Ciencias en tres aspectos: los propósitos de los exploradores en el marco del interés del gobierno argentino sobre los recursos naturales; la relación entre los académi$\cos$ y los distintos informantes locales sobre la flora; y los variados científicos. Las conclusiones muestran que entre 1870 y 1887 la Academia fue una institución importante para el inicio de la prospección científica de la flora argentina a través de los académicos extranjeros y nacionales, cuestión que generó las bases para una mayor comprensión de la vegetación nacional, su comparación con otras floras del mundo y su aprovechamiento económico. Por la valoración de la Botánica como una ciencia útil al Estado argentino, los académicos vincularon sus proyectos científicos con los intereses gubernamentales por la apropiación de los recursos vegetales aprovechando el saber local sobre la flora, cuestión que se materializó en listados,

* Esta investigación es parte del proyecto "La Botánica en la prensa de La Habana, Bogotá, Buenos Aires y México, 1820-1880. Aspectos políticos, sociales y económicos”, Facultad de Filosofía y Letras-UNAM.

** Universidad Nacional Autónoma de México, Ciudad de México, México, correo electrónico: rodrigo.vegayortega@hotmail.com. ORCID: https://orcid.org/0000-0002-3333-3536. 
cuadros, tablas, colecciones y libros especializados. La originalidad del trabajo reside en el análisis del conjunto de exploraciones botánicas en la Argentina a través del boletín en los años fundacionales de la Academia, pues la historiografía se ha pasado por alto a esta publicación y su relación con la historia de la botánica nacional. La fuente de la investigación se compone de los informes de cinco académicos, tanto extranjeros como nacionales: Georg Hieronymus, Paul Günther Lorentz, Ludwig Brackebusch, Fritz Kurtz y Eduardo L. Holmberg.

Palabras clave: botánica, academia, prensa, Argentina, exploración, ciencia.

\title{
Botanical explorations in the Bulletin of the National Academy of Sciences, Córdoba, Argentina (1874-1887)
}

\begin{abstract}
The objective of the research is to describe the development of botanical explorations organized by the National Academy of Sciences in the period 1874-1887 through the Bulletin of the National Academy of Sciences in three aspects: the purposes of the explorers in the framework of the Argentine government's interest in natural resources; the relationship between academics and the different local informants about the flora; and the different scientific results. The conclusions show that between 1870 and 1887 the Academy was an important institution for the beginning of the scientific prospecting of Argentine flora through foreign and national academics, an issue that generated the bases for a greater understanding of the national vegetation, its comparison with other floras of the world and their economic use. For the appreciation of Botany as a useful science to the Argentine State, academics linked their scientific projects with government interests for the appropriation of plant resources taking advantage of local knowledge about the flora, an issue that materialized in listings, tables, tables, collections and specialized books. The originality of the article lies in the analysis of the set of botanical explorations in Argentina through the bulletin in the foundational years of the Academy, since historiography has been overlooked in this publication and its relationship with the history of the national Botany. The source of the research consists of the reports of five academics, both foreign and national: Georg Hieronymus, Paul Günther Lorentz, Ludwig Brackebusch, Fritz Kurtz y Eduardo L. Holmberg.
\end{abstract}

Key words: botany, academy, press, Argentina, exploration, science. 


\section{INTRODUCCIÓN}

$\mathrm{E}^{\mathrm{n}}$ n años recientes el estudio de las exploraciones científicas por América Latina a lo largo del siglo XIX ha cobrado relevancia en la historiografía de la ciencia, ${ }^{1}$ en particular en la historia de la Botánica, pues gran parte de los objetivos de éstas se orientaron a la observación, acopio, descripción, designación y clasificación de la flora de cada país en el marco del estudio global de las especies del mundo. En la Argentina la puesta en marcha de gran parte de las exploraciones botánicas se llevó a cabo en el último tercio de la centuria a través de varias instituciones, una de ellas fue la Academia Nacional de Ciencias (ANC), cuya sede se encontraba en la ciudad de Córdoba. Ésta se fundó en 1869 para promover el desarrollo científico nacional, entre cuyos resultados de investigación se encuentran los escritos publicados en el Boletín de la Academia Nacional de Ciencias (BANC), desde su primer volumen de $1874 .^{2}$ En el largo proceso de desarrollo de la ANC, iniciado en 1869 , se cultivaron las ciencias físicas, naturales, médicas y geográficas a partir de la incorporación de científicos extranjeros y argentinos.

En el último tercio del siglo XIX la práctica botánica en la Argentina se materializó en varias exploraciones que fueron producto de los intereses de un conjunto de individuos en torno al escrutinio de la flora, ya fueran políticos, funcionarios, intelectuales, científicos y la élite económica. Estos individuos apuntalaron la investigación científica a partir de la constitución de bibliotecas, academias, gabinetes, institutos, escuelas y colecciones científicas, espacios donde se aspiraba a reflejar la riqueza, la diversidad y el valor económico de los recursos naturales argentinos. ${ }^{3}$

1 En el caso argentino nos referimos a Di Liscia, "La cornucopia del 'desierto'. Expediciones, científicos y recursos vegetales en la Pampa del siglo XIX y primera mitad del XX"; Mantegari, Germán Burmeister. La institucionalización científica en la Argentina del siglo XIX; Vizcaíno, Bargo y Fernicola, "Expediciones paleontológicas durante los siglos XIX y XX a la Formación Santa Cruz (Mioceno inferior, Patagonia) y destino de los fósiles"; Di Pasquale, "Entre la experimentación política y la circulación de saberes: la gestión de Bernardino Rivadavia en Buenos Aires, 1821-1827"; Bruno, "Eduardo L. Holmberg en la escena científica argentina. Ideas y acciones entre la década de 1870 y el fin-de-siglo"; Ortiz, "Las relaciones científicas entre las universidades de Córdoba y Göttingen (1860-1870): Wappäus, Cáceres y los Seis de Córdoba"; Depetris, "Charles Robert Darwin and Argentina's National Academy of Sciences"; Farro, "Redes y medios de transporte en el desarrollo de expediciones científicas en Argentina (1850-1910)"; Tognetti, "¿Catedrales de las ciencias o templos del saber? Los museos de ciencias naturales de Córdoba, Argentina, a fines del siglo XIX"; y Podgorny y Lopes, El desierto en una vitrina. Museos e historia natural en la Argentina, 1810-1890. El último libro aborda las complejas relaciones establecidas entre las expediciones financiadas por el Estado argentino y la formación de instituciones científicas a lo largo del siglo XIX.

2 El BANC se publicó hasta 2001.

Jardine y Spary, "The natures of cultural history", p. 9. 
La ciencia nacional, incluyendo la Botánica, fue "resultado de un largo y complejo proceso histórico gestado en las postrimerías de la época colonial y desarrollado durante todo el siglo XIX" ${ }^{4}$ a la par que se formaba y consolidaba el Estado nación, en cuyo seno se gestó paulatinamente una comunidad de naturalistas mediante la acumulación de conocimientos especializados y la conformación "de un espacio público que, aunque con limitaciones, hizo posible la creación de mecanismos de producción y reproducción de conocimientos y prácticas científicas" originados en Europa occidental. ${ }^{5}$ En la historiografía de la ciencia argentina, Víctor A. Ramos ha dividido el desarrollo científico en cinco épocas: colonial (siglos XVI a 1810), de Rivadavia (1810-1830), de los grandes viajeros (1830-1853), de la organización nacional (1853-1890) y de las grandes instituciones (siglo XX). ${ }^{6}$ A pesar de que en la primera mitad del siglo XIX la Argentina fue recorrida por notables viajeros extranjeros, la segunda mitad no es menos representativa de este proceso, con la salvedad que las instituciones nacionales se sumaron a la organización de exploraciones de forma continua por todo el territorio.

En la historiografía también se ha analizado el papel de la ANC en el fortalecimiento de la ciencia nacional, como lo demuestran los estudios de Luis Tognetti, José Babini, Marcelo Montserrat, Verónica Tozzi, Carlos Page, Telasco García Castellanos, Maria Cristina Vera, Remedios Ferrero y César Lorenzano, sin que ninguno se haya centrado en las exploraciones botánicas ni en el $B A N C$ en el lapso de esta investigación.

En las siguientes páginas se propone describir y mostrar el desarrollo de las exploraciones botánicas organizadas por la ANC en el período 1874-1887 a través del $B A N C$ en tres aspectos: los objetivos de los exploradores en el marco del interés del gobierno argentino sobre los recursos naturales; la relación entre los académicos y los distintos informantes locales sobre la flora; y la variedad de resultados científicos. Los límites temporales de la investigación comprenden el inicio del $B A N C$, cuyo primer tomo incluyó las exploraciones de 1870 a 1874 , mientras que el año de 1887 representa un parteaguas en el fortalecimiento institucional de la ANC que repercutió en la realización de nuevas exploraciones. ${ }^{7}$ Entre 1870 y 1887 se inició la prospección institucional de la flora argentina a través de los académicos extranjeros y nacionales, cuestión que generó las bases para una mayor

\footnotetext{
Depetris, "Charles Robert Darwin and Argentina's National Academy of Sciences", p. 9.

López Ocón, "La formación de un espacio público para la ciencia en la América Latina durante el siglo XIX", p. 207.

6 Ramos, "Doscientos años de Ciencias de la Tierra en la Argentina", p. 395.

7 Además, en 1889 la ANC se instaló en un moderno edificio apropiado para sus tareas de investigación en que se ubicó la colección botánica.
} 
comprensión de ésta, su comparación con otras floras del mundo y su aprovechamiento económico.

La fuente de la investigación se compone de los informes de cinco académicos, quienes son: Georg Hieronymus (1845-1921) ${ }^{8}$ (“Observaciones sobre la vegetación de la Provincia de Tucumán” y "Continuación. Observaciones sobre la vegetación de la Provincia de Tucumán”, 1874), Paul Günther Lorentz (1835-1881) ("Informe científico sobre el resultado de los viajes y excursiones botánicas hechas desde el mes de Noviembre de 1870 hasta el mismo mes de 1872", 1875), Ludwig Brackebusch (1849-1906) ${ }^{10}$ ("Viaje a la Provincia de Jujuy. Discursos pronunciados en el Instituto Geográfico Argentino (Sección Córdoba"), 1883), Fritz Kurtz (1854-1921)11 ("Informe preliminar de un viaje botánico efectuado por orden de la Academia Nacional de Ciencias en Córdoba, en las provincias de Córdoba, San Luis y Mendoza hasta la frontera de Chile, en los meses de diciembre 1885 a febrero de 1886", 1886) y Eduardo L. Holmberg (1852-1937) 12 ("Viaje a Misiones", 1887), único académico nacional. Se eligieron estos escritos por ser los que acopiaron mayor cantidad de información botánica en el BANC. En el período que abarca esta investigación se reportaron al $B A N C 42$ escritos como resultado de las expediciones científicas (botánicas, geográficas y geológicas) realizadas por los académicos.

La metodología de la investigación se basa en la historia social de la ciencia al reconocer la importancia de la sociabilidad científica en la emergencia de las políticas científicas que se diseñan e implementan en los cuerpos consultivos del Estado con el propósito de reconocer los recursos naturales, en este caso la prospección impulsada por el gobierno argentino mediante la ANC. Ésta conformó un grupo de expertos que mediante la sociabilidad académica, como expone Emma Spary, construyeron "la credibilidad del conocimiento que se difundía a partir de la práctica científica que

8 Botánico alemán que emigró a la Argentina en 1872 para convertirse en ayudante de Lorentz. En 1881 publicó el catálogo Plantae diaphoricae florae argentinae. En 1883 regresó a Alemania y en 1892 fue designado curador del Museo de Historia Natural de Berlín.

9 Botánico alemán fundador de la biogeografía de las plantas. Desde 1875 fue designado profesor de Botánica en el Colegio Nacional de Concepción del Uruguay, después de su separación de la ANC. Participó en la Expedición al Río Negro de 1879.

10 Geólogo alemán encargado del acervo mineralógico de la ANC desde 1875. En 1888 regresó a Alemania. En 1891 publicó "Mapa geológico del interior de la República Argentina".

11 Botánico alemán encargado de la Cátedra de Botánica de la ANC de 1884 a 1915. Realizó exploraciones por la Argentina de 1885 a 1900.

12 Médico y naturalista argentino. Fundador de la revista El Naturalista Argentino. En 1888 fue designado director del Jardín Zoológico de Buenos Aires. Fue profesor de la Escuela Normal de Profesores y la Facultad de Ciencias Exactas, Físicas y Naturales de la Universidad de Buenos Aires. 
se validaba entre pares" y en concordancia con las demandas políticoeconómicas del momento. ${ }^{13}$ También se retoma la propuesta de John V. Pickstone acerca de que las ciencias naturales (Botánica, Zoología y Mineralogía) desde el siglo XVIII se orientaron hacia "el estudio 'de lo que tenemos' en el planeta y su sistematización en colecciones públicas o privada" a través de un método científico basado en observar, recolectar, describir, nombrar y clasificar. ${ }^{14}$ Este método se evidencia en los escritos del BANC.

Si bien la historiografía clásica ${ }^{15}$ enfatiza el devenir azaroso y conflictivo de la ANC, también es cierto que desde 1869 hubo exploraciones y colecta de especímenes naturales del país, como se refleja en el BANC. Así, la constitución de la ANC, entre otras instituciones, fue parte del largo proceso de la ciencia argentina en que las disciplinas dejaron "de ser una empresa individual para convertirse en un asunto público de interés social" en el marco de la consolidación del estado nacional de la segunda mitad del siglo XIX a inicios del XX. ${ }^{16}$ Los gobernantes en este período se interesaron en desarrollar expediciones científicas para reconocer los recursos del territorio, la naturaleza y la población que se conocían escasamente desde el final de la época colonial. Hay que tomar en cuenta que a partir de la década de 1860 "el discurso político comenzaba a delinear una doctrina de progreso ${ }^{17}$ en la que, según se proclamaba, la ciencia jugaba un rol central como instrumento capaz de potenciar el progreso" socioeconómico que se anhelaba en la Argentina. ${ }^{18}$

La ANC se inscribió en la tendencia de los Estados nación por erigir cuerpos de expertos a su servicio. Las primeras academias al servicio del Estado monárquico fueron la Accademia dei Lincei (1603) en Roma y la Accademia

13 Spary, "Of Nutmegs and Botanists. The Colonial Cultivation of Botanical Identity", p. 188.

14 Pickstone, Ways of knowing. A new history of science, technology and medicine, p. 11.

15 Nos referimos como ejemplo a los trabajos de Tognetti y Page, La Academia Nacional de Ciencias. Etapa Fundacional-Siglo XIX; Babini, Historia de la ciencia en la Argentina; García Castellanos, Breve historia de la Academia Nacional de Ciencias de Córdoba, República Argentina; Vera, "Notas para la historia de la universidad en Argentina"; Montserrat, Ciencia, historia y sociedad en la Argentina del siglo XIX; y Lorenzano, Por los caminos de Leloir. Estructura y desarrollo de una investigación Nobel.

16 Azuela, "La institucionalización de las ciencias en México durante el porfiriato", p. 73.

17 La noción de progreso decimonónica indica que la ciencia era el pilar para el cambio de las naciones mediante la acumulación de conocimiento y técnicas útiles en términos socioeconómicos que a su vez repercutían en las etapas del proceso civilizatorio de las sociedades. El progreso científico requería de instituciones apoyadas por el estado-nación para lograr sus propósitos acumulativos y civilizatorios. En esta investigación se entrecomilla el término progreso para diferenciar los significados decimonónico y actual. Nisbet, Historia de la idea de progreso, p. 334.

18 Ortiz, "Las relaciones científicas entre las universidades de Córdoba y Göttingen (18601870): Wappäus, Cáceres y los Seis de Córdoba”, p. 94. 
del Cimento (1657) en Florencia, la Royal Society en Londres (1660), l'Académie Royale des Sciences en París (1666), la Academia Prusiana de las Ciencias (1700) en Berlín, la Academia de Ciencias de San Petersburgo (1724), la Real Academia de Medicina y Ciencias Naturales (1734) en Madrid y la Real Academia de Ciencias de Suecia (1739) en Estocolmo. Desde entonces las academias fueron la cabeza de la política científica de los Estados europeos en cuanto a erigir un orden aristocratizante de la actividad científica. ${ }^{19}$ Esta tendencia se presentó en América Latina en el siglo XIX, por ejemplo, en Colombia (1826), Cuba (1861), México (1865), entre otros países.

La diferencia principal entre las agrupaciones científicas y las académicas científicas "era la estabilidad que les proporcionaba a las últimas el patrocinio real y por otro, su carácter de ejecutoras de las iniciativas científicas oficiales, como cortes de expertos en su ámbito cultural particular" bajo el amparo del Estado y el gobernante. ${ }^{20}$ Los académicos también recibían la dieta "que les otorgaba su pertenencia al más alto órgano de reunión de la intelectualidad, un privilegio que los diferenciaba radicalmente del resto de los hombres de ciencia de su tiempo". ${ }^{21}$

Las academias gozaron de un local propio para acondicionar una sala de juntas, la biblioteca, el archivo y, en ocasiones, un museo y un laboratorio, además de la capacidad para publicar revistas, folletos, libros y mapas. Desde el inicio, éstas "tenían un reglamento interno para normar sus actividades y regular los mecanismos de admisión; un protocolo para el ingreso de sus miembros; y una serie de normas para la organización de sus trabajos; realizaban reuniones regulares con sus agremiados" y rendían informes anuales al Estado. ${ }^{22}$

En el caso de las academias hispanoamericanas creadas después de las independencias, el objetivo político más "frecuente era adelantar y propagar las ciencias naturales, con énfasis en el conocimiento" nacional de los recursos de flora, fauna y minerales, dimensión del territorio, características de la población y fomento a los ramos económicos, todo ello bajo la utilidad de la ciencia. ${ }^{23}$

19 Azuela y Vega y Ortega, "La Academia Imperial de Ciencias y Literatura de México, 18651866", p. 57.

20 Hahn, The Anatomy of a Scientific Institution. The Paris Academy of Sciences, 1666-1803, p. 47.

21 Capel, "El asociacionismo científico en Iberoamérica. La necesidad de un enfoque globalizador", p. 413.

22 Pruna, La Real Academia de Ciencias de La Habana 1861-1898, p. 59.

23 Capel, "El asociacionismo científico en Iberoamérica. La necesidad de un enfoque globalizador", p. 412. 


\section{PANORAMA DE LA CIENCIA ARgENTINA ${ }^{24}$}

El desarrollo de la ciencia en la Argentina inició en el período colonial, aunque fue hasta el inicio del período independiente que se fundaron las primeras instituciones modernas en el país, por ejemplo, la Universidad de Buenos Aires, creada en 1821, cuya "estructura departamental se realizó agrupando distintas instituciones heredadas de la época colonial" y en 1823 se decretó la fundación del Museo Público de Buenos Aires bajo la presidencia de Bernardino Rivadavia (1780-1845). ${ }^{25}$ También hubo agrupaciones, como la Sociedad Literaria (1822) y la Academia de Medicina (1822). ${ }^{26}$ En las primeras décadas de vida soberana se mantuvo la actividad científica, pero ceñida a las convulsas circunstancias políticas y económicas.

Fue hasta la segunda mitad de la centuria que se marcó un cambio en el desarrollo científico argentino a partir de la fundación de nuevas instituciones con el propósito de afianzar el reconocimiento de los recursos naturales y territoriales, así como establecer con claridad las fronteras regionales e internacionales, y modernizar los rubros productivos. En la época "de la organización nacional" se fundaron en Buenos Aires la Sociedad Científica Argentina (1872), el Zoológico de Buenos Aires (1874), el Instituto Geográfico Argentino (1879) y la Sociedad Geográfica Argentina (1881). ${ }^{27}$ Además, la Universidad de Buenos Aires amplió sus capacidades de formación científica al crearse en 1865 la Facultad de Ciencias Exactas conformada por científicos italianos; ${ }^{28}$ y en 1875 se inauguraron los estudios de Doctorado en Ciencias Naturales en el marco del proyecto gubernamental orientado a renovar las profesiones en la Argentina. En la época "de las grandes instituciones" destaca la Dirección de Geología y Minas (1904).

En otras ciudades hubo nuevas instituciones científicas, como el caso de La Plata, en que se fundó el Museo General (1884). En la ciudad de Córdoba se fundó la Universidad Mayor de San Carlos en 1613, aunque se nacionalizó en 1854. En esta ciudad se erigieron la Academia Nacional de Ciencias

24 Este apartado tiene como propósito contextualizar de manera sintética la fundación y desarrollo inicial de la ANC en el marco de los espacios de la ciencia argentina, sin pasar por alto que se trata de un proceso amplio y complejo, que no es posible presentar en breves cuartillas.

25 Di Pasquale, "Entre la experimentación política y la circulación de saberes: la gestión de Bernardino Rivadavia en Buenos Aires, 1821-1827”, p. 60.

26 González Bernaldo de Quirós, "Sociabilidad y opinión pública en Buenos Aires (18211852)", p. 664.

27 Curto, Jáuregui, Escuela, Lascano y Pena, "La fundación de GÆA Sociedad Argentina de Estudios Geográficos-1922”, p. 3.

28 García Castellanos, Breve historia de la Academia Nacional de Ciencias de Córdoba, República Argentina, p. 15. 
(1869), el Observatorio Nacional Argentino (1870), la Oficina Meteorológica Argentina (1872) y la Facultad de Ciencias Físico-Matemáticas (1876) de la universidad. ${ }^{29}$ "El establecimiento de estas instituciones científicas pioneras, aún hoy en plena actividad, formó parte de una política de promoción de las ciencias" por parte de los presidentes Domingo Faustino Sarmiento (1811-1888) y Nicolás Avellaneda (1837-1885). ${ }^{30}$

En la década de 1870 en la Universidad Nacional de Córdoba se constituyeron las facultades de Ingeniería Civil y de Medicina, con las cuales se "ofrecían las perspectivas profesionales que la sociedad cordobesa había ambicionado para sus jóvenes". ${ }^{31}$ Esta universidad hasta la década de 1880 fue de las pocas instituciones “de educación superior con que contó el estado nacional para llevar adelante su política de desarrollo de las ciencias en el país". 32

Antes de la década de 1870 los jóvenes argentinos carecían de una escuela de naturalistas dónde profesionalizarse en Botánica y Zoología. Por ello, el país adolecía de estos profesionales, por lo que "la mayoría de los hombres de ciencia en la Argentina eran extranjeros y habían obtenido sus credenciales en sus países de origen", mientras varios amateurs argentinos destacaban en las ciencias naturales, como Francisco Pascasio Moreno, Florentino Ameghino y Juan Ambrosetti, quienes "no contaron con formación universitaria". 33

De acuerdo con la "Reseña histórica sobre la fundación y progresos de la Academia de Ciencias Exactas en Córdoba" (1874) del doctor Germán Burmeister, su primer director, la corporación científica en un inicio había sido respaldada por el presidente Sarmiento como parte de su proyecto político de renovación de la Universidad Nacional de San Carlos mediante la Ley $\mathrm{N}^{\circ} 322$ de 1869 con miras a la modernización de las profesiones ahí impartidas. Para ello, el mandatario ordenó la creación de la Facultad de Ciencias Matemáticas y Físicas con el propósito de "formar maestros aptos para enseñar dichas ciencias en los colegios nacionales" y constituir un centro para la enseñanza superior a partir de "un gremio de sabios aptos para

29 Babini, Historia de la ciencia en la Argentina, p. 95.

30 Mantegari, "Germán Burmeister. La institucionalización científica en la Argentina del siglo XIX”, p. 12.

31 Ortiz, "Las relaciones científicas entre las universidades de Córdoba y Göttingen (18601870): Wappäus, Cáceres y los Seis de Córdoba”, p. 313.

32 Tognetti, “¿Catedrales de las ciencias o templos del saber? Los museos de ciencias naturales de Córdoba, Argentina, a fines del siglo XIX”, p. 36.

33 Bruno, "Eduardo L. Holmberg en la escena científica argentina. Ideas y acciones entre la década de 1870 y el fin-de-siglo", p. 121. 
estudiar y dar a conocer las riquezas naturales del país argentino". ${ }^{34}$ La renovación universitaria estuvo delineada por el positivismo que en la Argentina se había erigido como el camino ideológico con el cual transformar la sociedad desde el punto de vista racional y material. ${ }^{35}$ Bajo esta ideología, en América y Europa durante el último tercio del siglo se fundaron paulatinamente facultades y escuelas profesionales para la formación de los nuevos cuadros científicos-tecnológicos que requería cada estado nacional, como el argentino, para hacer realidad el "progreso".

El modelo fundacional de la ANC retomó la estructura alemana en que "facultad y academia coexistían en las principales universidades de esa época, por ejemplo, en Göttingen o Halle", pues los académicos se dedicaban a la docencia y la investigación universitarias con énfasis en la solución de las problemáticas del Estado y la sociedad. ${ }^{36}$ La reforma de la Universidad implicó contratar a ocho profesores europeos que se integrarían a la nueva Facultad. Burmeister escribió a sus antiguos colegas de la Real Universidad Prusiana de Halle para que alentaran a algunos científicos a emigrar a la Argentina. ${ }^{37}$ El gobierno estaba dispuesto a contratar a dos profesores de Matemáticas, uno de Física, uno de Química, uno de Mineralogía y Geología, uno de Botánica, uno de Zoología y uno de Astronomía. El sueldo mensual ofrecido sería de doscientos pesos fuertes, más una pequeña suma para costear los gastos de la exploración. La transferencia de profesionales de la ciencia de Europa occidental a Latinoamérica fue un mecanismo constante en la política educativa, implantada primero por los estados monárquicos desde finales del siglo XVIII y después por los estados nacionales a partir de la década de 1820. Esta transferencia se basó en la escasa institucionalización de la educación profesional en Latinoamérica, razón por la cual varios mandatarios de la región atrajeron a científicos europeos para que instruyeran a las futuras generaciones locales. Una política científica que reforzó la dependencia ${ }^{38}$ epistémica entre las naciones latinoamericanas con los países de Europa occidental.

34 Burmeister, "Reseña histórica sobre la fundación y progresos de la Academia de Ciencias Exactas en Córdoba, por el director científico de la misma", p. 1.

35 Véase Saur y Servetto (coord.), Universidad Nacional de Córdoba. Cuatrocientos años de historia, 2 vols.

36 Ortiz, "Las relaciones científicas entre las universidades de Córdoba y Göttingen (18601870): Wappäus, Cáceres y los Seis de Córdoba”, p. 312.

37 Burmeister, "Reseña histórica sobre la fundación y progresos de la Academia de Ciencias Exactas en Córdoba, por el director científico de la misma", p. 1.

38 La dependencia epistémica se refiere a las relaciones asimétricas establecidas entre dos sociedades en aspectos teóricos y prácticos de la ciencia a partir de la circulación del conocimiento especializado por el mundo. La dependencia establece que una sociedad es generadora de dicho conocimiento y la comunica a otras a partir del trabajo de sus especialistas 
El gobierno argentino contrató el 12 de mayo de 1870 al doctor Max Siewert (1843-1890) de la Universidad de Halle, especialista en Química, y al doctor Paul Günther Lorentz de la Universidad de Münich, especialista en Botánica. ${ }^{39}$ En noviembre arribó a la Argentina el doctor Alfred W. Stelzner (1840-1895) de la Academia Real de Minería de Sajonia, en Freiberg, como profesor de Mineralogía. ${ }^{40}$ En noviembre de 1871 se contrató al doctor Hendrik Weyenbergh (1842-1885) de Harlem, Holanda, para la Cátedra de Zoología, quien llegó a Córdoba hasta mayo de $1872 .{ }^{41}$ En 1873 se contrató al doctor Carl Schultz Sellack (1841-1879) para la cátedra de Física y al doctor Christian August Vogler (1841-1925), profesor de Geodesia e Hidrotécnica de la Academia Politécnica de Múnich, como catedrático de Matemáticas. ${ }^{42}$ Estos científicos ya habían iniciado una carrera académica en sus países de origen y contaban con las relaciones necesarias para ser aprobados por el director de la ANC.

Burmeister informó que los académicos contratados carecían de la fluidez necesaria en el idioma castellano, por lo que aún no se dedicaban a las tareas docentes con la regularidad necesaria, aunque se habían concentrado en el "estudio científico del país" con énfasis en sus recursos naturales y territoriales. ${ }^{43}$ Cabe señalar que desde 1862 Burmeister ocupaba el cargo de director del Museo Público de Buenos Aires, ${ }^{44}$ por lo que delegó momentáneamente la dirección en el doctor Adolf Doering (1848-1925), ${ }^{45}$ en calidad de sustituto, y también lo designó redactor del BANC para dar a conocer "todos los sucesos científicos y oficiales de la Academia al público interesado". ${ }^{46}$ Pocos años después de la fundación de la ANC se dieron los primeros pasos para consolidar su vida científica, fundando el órgano que publicitaría las actividades de los miembros con el propósito de legitimar su existencia ante el gobierno, la sociedad y los intelectuales. Esto era común en las academias nacionales de la época.

plasmado en viajes, impresos, colecciones, instrumentos y cátedras. Polo, "Colonialidad del poder y violencia epistémica en América Latina”, p. 30.

39 Burmeister, "Reseña histórica sobre la fundación y progresos de la Academia de Ciencias Exactas en Córdoba, por el director científico de la misma", p. 1.

40 Ibid., p. 2.

41 Ibid.

42 Ibid.

43 Ibid.

44 García Castellanos, Breve historia de la Academia Nacional de Ciencias de Córdoba, República Argentina, p. 19.

45 Doering había llegado a Córdoba en 1872 en calidad de ayudante de la cátedra de Química. Después de la renuncia del Dr. Siewert, Doering ocupó la cátedra.

46 Burmeister, "Reseña histórica sobre la fundación y progresos de la Academia de Ciencias Exactas en Córdoba, por el director científico de la misma”, p. 3. 
A inicios de 1874 por diferencias con Burmeister fueron separados de su cargo Lorentz y Stelzner. Como sustituto del segundo se designó a Ludwig Brackebusch. ${ }^{47}$ En mayo de 1874 dimitieron los profesores Siewert, Wyenbergh y Vogler, quienes fueron reemplazados por el mencionado Doering, catedrático de Química, el doctor Hermann von Ihering (18501930), catedrático de Zoología, y el doctor Oscar Doering (1844-1917), catedrático de Matemáticas, además del doctor Georg Hieronymus, catedrático de Botánica. ${ }^{48} \mathrm{~A}$ pesar de las problemáticas entre los académicos en los primeros años de vida de la ANC, el proyecto continuó por varias décadas con nuevos especialistas, algunos de los cuales efectuaron exploraciones científicas en distintos años.

El reglamento de la ANC de 1878 estableció en el artículo $3^{\circ}$ que sus tareas sustantivas serían:

$1^{\circ}$ Servir de consejo consultivo al Gobierno en los asuntos referentes a las ciencias que cultiva el Instituto.

$2^{\circ}$ Explorar y estudiar el país en todas las ramificaciones de la naturaleza.

$3^{\circ}$ Hacer conocer los resultados de sus exploraciones y estudios por medio de publicaciones.

$4^{\circ}$ Mantener relaciones de canje con otras sociedades científicas. ${ }^{49}$

Sobre la ANC, la reglamentación resalta la participación en las decisiones gubernamentales a partir del parecer de los sabios sobre las problemáticas del país; y enfatiza la circulación del conocimiento especializado por medio de los impresos y el intercambio material con corporaciones científicas similares del mundo. Ambos lineamientos tendieron al fortalecimiento institucional.

El artículo $16^{\circ}$ expresó que los socios llevarían a cabo exploraciones durante las vacaciones de la Universidad. ${ }^{50} \mathrm{El}$ artículo $17^{\circ}$ estableció que las localidades a explorarse se escogerían por la Comisión Directiva prefiriendo aquellas de interés para el gobierno nacional, además de que cada explorador remitiría al Ministerio de Instrucción Pública un informe de la operación practicada. ${ }^{51}$ Este artículo indica que las exploraciones se mantuvieron como actividad fundamental de la ANC, aunque se orientarían hacia los intereses gubernamentales y se mantendría un control oficial al entregarse un informe no sólo al director, sino también al ministro. Esto supuso inicialmente una

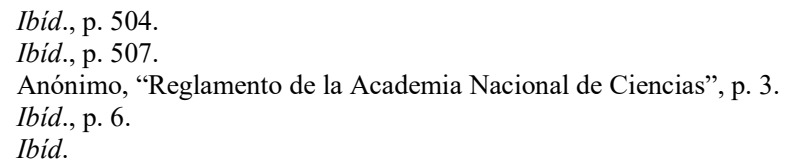


menor libertad por parte de los académicos, pero un mayor apoyo de recursos estatales. Hay que tomar en cuenta que en la Argentina, como el resto de Latinoamérica, "la mayor parte del territorio estaba por recorrer" y con la nueva reglamentación se insistió en la identificación de "nuevos productos naturales comercializables" que modernizarían la economía nacional. ${ }^{52}$

Si bien varios de los exploradores extranjeros se incorporaron a las instituciones argentinas y contribuyeron a su desarrollo académico, hubo otros "que pasaron por el país para luego publicar sus investigaciones en Europa sin contar con la preparación para captar las especificidades de la Argentina". ${ }^{53}$ Los científicos extranjeros, tanto los que se asentaron en el país como los que regresaron a Europa, fueron "exploradores avanzados del capital europeo [...] como expertos en la búsqueda de recursos explotables, contactos y contratos con las élites locales, información sobre potenciales emprendimientos" económicos. ${ }^{54}$

Los viajes científicos, ya fueran grandes o pequeñas expediciones, tuvieron por objetivo epistémico "transmutar los objetos de la naturaleza en móviles que permiten la acción a distancia", ${ }^{55}$ con lo cual las instituciones que las patrocinaban amplificaban su capacidad "de reunir información y actuar a distancia" sobre los recursos naturales. ${ }^{56}$ Una aspiración de la ANC desde su fundación y plasmada en su reglamento.

En el caso de los viajes con objetivos botánicos, uno de los resultados principales fue la gama de inventarios florísticos de la Argentina, que en general se publicaron por naturalistas extranjeros, aunque contaron con la participación de los botánicos locales en la confección de catálogos de la flora de distintas regiones, de los que actualmente se conoce poco. ${ }^{57}$ Las expediciones de los naturalistas europeos en América "jugó un rol importante en la incorporación del conocimiento producido en otras culturas", pues el acopio e inventario de la flora no sólo se constituyó a partir de los especímenes, sino también de los aspectos culturales con que cada especie era entendida en un entramado cultural en cada localidad argentina. ${ }^{58}$

52 Becerra y Restrepo, "Las ciencias en Colombia: 1783-1990. Una perspectiva históricosociológica", p. 38.

53 Bruno, "Eduardo L. Holmberg en la escena científica argentina. Ideas y acciones entre la década de 1870 y el fin-de-siglo", p. 128.

54 Pratt, Ojos imperiales. Literatura de viaje y transculturación, p. 271.

55 Farro, "Redes y medios de transporte en el desarrollo de expediciones científicas en Argentina (1850-1910)", p. 691.

56 Vizcaíno, Bargo y Fernicola, "Expediciones paleontológicas durante los siglos XIX y XX a la Formación Santa Cruz (Mioceno inferior, Patagonia) y destino de los fósiles”, p. 233.

57 Josa, "La Historia Natural en la España del siglo XIX: Botánica y Zoología", p. 128.

58 Massarani y De Castro Moreira, "Popularisation of Science: Historical Perspectives and Permanent Dilemmas", p. 76. 


\section{Preparativos de las EXPLORACIONES}

Los cinco artículos sobre exploraciones botánicas estuvieron conformados por una introducción en que se justificaba la importancia de efectuar este tipo de prácticas científicas por parte de la ANC. Desde el primer volumen del $B A N C$ de 1875 se publicaron este tipo de escritos para dar a conocer a la opinión pública las actividades de los miembros. Esto fue parte del proyecto fundacional del doctor Burmeister a partir de su experiencia como editor de los Anales del Museo Público de Buenos Aires, iniciados en 1864, para dar a conocer "los objetos de historia natural nuevos o poco conocidos conservados en el establecimiento". ${ }^{59}$ En el siglo XIX las publicaciones científicas "fueron creadas como vehículo de difusión y discusión de la ciencia", así como medio de validación académica de las comunidades científicas, en especial en sus primeros años de formación. ${ }^{60}$

El académico Paul Günther Lorentz en el "Informe científico sobre el resultado de los viajes y excursiones botánicas hechas desde el mes de noviembre de 1870 hasta el mismo mes de 1872" (1875) señaló que había sido comisionado por el gobierno argentino para explorar el país, pues su "flora era una de las menos conocidas" del mundo, a pesar de que tiempo atrás algunos naturalistas "habían remitido a Europa colecciones, pero solo se tenían reseñas aisladas, porque nunca se había hecho una investigación metódica", como la que exponía el autor. ${ }^{61} \mathrm{Se}$ aprecian dos problemáticas. Primero, la ausencia de información sistematizada sobre la naturaleza de la joven república, una cuestión que representaba un obstáculo para el aprovechamiento de los recursos naturales a partir de la directriz de los gobiernos provinciales y nacional con el fin de establecer políticas económicas y de colonización. Segundo, que la mayor parte de la información botánica se encontraba en instituciones científicas europeas, por lo que existía una dependencia epistémica entre la Argentina y los centros académicos del Viejo Mundo. Ambas cuestiones se trataban de solucionar a partir de las actividades de los académicos de la ANC.

Los itinerarios del expedicionario consistieron en recorrer los alrededores de Córdoba para luego explorar desde esta ciudad hacia San Pedro, Chañar de San Francisco, Loreto, Santiago del Estero, la Sierra de Aconquija, Siambón, la Ciénaga, Tafí, el Paso de Infiernillos, el Valle de Santa María,

59 Carreras, "Unas carrera científica entre Prusia y Argentina: el itinerario de Hermann Burmeister", p. 96.

60 Massarani y De Castro Moreira, "Popularisation of Science: Historical Perspectives and Permanent Dilemmas", p. 77.

61 Lorentz, "Informe científico sobre el resultado de los viajes y excursiones botánicas hechas desde el mes de noviembre de 1870 hasta el mismo mes de 1872", p. 92. 
el campo del Arenal, las minas de Capillitas, Pilciao, Belén, Yakutula (estancia del señor Schickendantz), ${ }^{62}$ "donde permanecimos algún tiempo, haciendo excursiones más o menos largas, especialmente una, interesantísima y fecunda en resultados", la Laguna Blanca, los altos valles de Las Granadillas, el Fuerte de Andalgalá hasta las "hermosas y fértiles llanuras de Tucumán, por las cuales volvimos a la ciudad" de Córdoba. ${ }^{63}$ Durante dos años, Lorentz y su comitiva recorrió el país como nunca se había efectuado antes por parte de naturalistas al servicio del Estado argentino. La información y especímenes recabados por el académico fueron el inicio del acervo museístico de la ANC con que se beneficiarían las futuras generaciones de científicos argentinos.

Lorentz expuso su metodología botánica para validar los resultados científicos entre los lectores, además de justificar los recursos gubernamentales que gozó para efectuar sus actividades durante dos años. A continuación se enumera su metodología:

$1^{\circ}$ Coleccionar lo más completamente posible todas las especies de plantas que viven en el país, sin descuidar ni aun las más comunes e insignificantes; $2^{\circ}$ Clasificarlas con la mayor seguridad posible; $3^{\circ}$ Averiguar el área a que cada planta está limitada y los centros de densidad de las áreas en que la planta se extiende; $4^{\circ}$ Anotar la parte que tiene cada planta en la composición de las formas de la vegetación y la frecuencia absoluta o relativa con que se encuentra en diferentes puntos o regiones; $5^{\circ}$ Hacer un cuadro de la vegetación del país, tan completo como fuese posible con la reunión de estos datos y su descripción topográfica; $6^{\circ}$ Tratar de averiguar las causas que determinan los diferentes rasgos de este cuadro, que consisten: una parte en los agentes actuales, como son la altura sobre el nivel del mar, el clima general, la cantidad de humedad y su distribución en las diferentes estaciones del año, la exposición y orientación de los lugares donde se encuentran las plantas, las propiedades físicas y químicas del suelo, etcétera; y otra en la historia geológica del país, de la cual solo podemos darnos cuenta de una manera muy incompleta; $7^{\circ}$ Atender a los puntos de vista de aplicación práctica, llamando la atención sobre las plantas que puedan ser útiles y tal vez formar la base de una industria; indicando las plantas que por la naturaleza de su vegetación ofrecen la probabilidad de propagarse bien, o avisando que deben desecharse otras que acaso en este clima y suelo no darían resultado. ${ }^{64}$

62 Un profesor alemán contratado para el Colegio de Tucumán.

63 Lorentz, "Informe científico sobre el resultado de los viajes y excursiones botánicas hechas desde el mes de noviembre de 1870 hasta el mismo mes de 1872 ”, p. 95.

64 Ibid., p. 93. 
La metodología de Lorentz fue común en el último tercio del siglo en cuanto a determinar la flora de una región mediante parámetros positivos que requerían de la exploración durante largo tiempo para que el naturalista conociera in situ las especies. Durante la exploración era indispensable coleccionar especímenes de todo tipo, anotando la mayor cantidad de datos sobre el sitio de colecta. Posterior a esta fase, en la ANC se emprendía la clasificación de lo colectado y después se determinaba la distribución geobotánica a partir de los especímenes. A veces, estos datos en forma de listados botánicos eran transformados en una información visual de conjunto, como tablas, cuadros y sinopsis, como la propuesta de Lorentz.

Con los listados botánicos y la colección, Lorentz se dio a la tarea de iniciar una explicación sobre la flora del centro-norte argentino en cuanto a los elementos ambientales que hacían posible su distribución, así como elaborar un bosquejo de los aspectos evolutivos de las especies, para lo cual se requerían datos geológicos, hasta entonces carentes en la Argentina. Por último, el autor proporcionó noticias de la utilidad de algunas especies a partir de la información proporcionada por los habitantes de esas regiones, al igual que datos generados por los académicos. Esta metodología también fue similar a la expuesta en los escritos botánicos de los otros académicos presentes en esta investigación.

Para Lorentz las primeras sistematizaciones de la flora argentina representaban "una conquista para la ciencia" y eran merecedoras de comunicarse en el $B A N C$ para la comunidad científica internacional y la nacional en ciernes. ${ }^{65}$ La publicación del informe mostró la contribución científica de Lorentz a la exploración de la república y sirvió para legitimar sus actividades como académico.

En 1874 el naturalista Georg Hieronymus, al dar a conocer su informe relativo a la vegetación tucumanense, indicó que ante la carencia de estudios científicos sobre la región se había propuesto como meta inicial la colecta y observación de sus bosques y selvas, reconociendo con especímenes, dibujos y descripciones que entre ambos paisajes "hay una transición a otro vecino por medio de formaciones secundarias, que participan de las componentes en su carácter, y ya se parecen más a uno, o más a otro de las formaciones principales limítrofes, según la mezcla y composición" de las especies ${ }^{66}$ El segundo propósito sería posterior a la exploración, cuando Hieronymus propondría "el carácter general de las formaciones principales con exactitud"

65 Ibid.

66 Hieronymus, "Continuación. Observaciones sobre la vegetación de la Provincia de Tucumán”, p. 299. 
de la provincia. ${ }^{67}$ Las palabras del académico se asemejan a la metodología de Lorentz en cuanto a recolectar y describir especies, efectuar una diferenciación paisajística a partir de la distribución de éstas para distinguir la selva del bosque, así como reconocer sus puntos de contacto dependiendo de la latitud, altitud, clima, entre otras variables.

Hieronymus consideró imprescindible iniciar el examen de la flora centrándose en el carácter "especial de las diversas localidades", cuyo complemento serían "las noticias locales sobre la distribución de las plantas de muchas partes" de Tucumán, pues la biblioteca de la ANC carecía de monografías científicas "que suministren los materiales necesarios para ocuparnos provechosamente a detalle" de cada especie. ${ }^{68}$ Los académicos de los primeros años de la ANC reconocieron que estaban sentando las bases de la Botánica en la Argentina, por lo que sus informes, colecciones y monografías servirían para las futuras generaciones. De ahí que Hieronymus expusiera en su metodología iniciar por los paisajes, como entidades botánicas generales, fáciles de reconocer por cualquier observador, dejando para el futuro el dedicarse a los grupos taxonómicos específicos.

En 1883 Ludwig Brackebusch publicó su informe sobre la exploración emprendida a la provincia de Jujuy en que señaló que después de varios años residiendo en la Argentina se había percatado de que en muchas localidades "civilizadas", es decir, ciudades de origen colonial, se tenían "menos datos geográficos y topográficos" que de las provincias recién conquistadas ${ }^{69}$ por el Estado argentino que se estaban "preparando para la civilización y la cultura", gracias a las comisiones científicas que acompañaban al ejército, por ejemplo, en la llamada "Conquista del Desierto" (1878-1885). ${ }^{70}$ El naturalista alabó al gobierno por dotar de recursos a los científicos con el propósito de elaborar la cartografía del territorio habitado por "los indios de la Pampa", cuyos mapas "instructivos y bastante detallados" propiciarían la colonización “civilizatoria”, además de la apropiación política del territorio. ${ }^{71}$ No obstante, Brackebusch recalcó que aún faltaba el reconocimiento científico del norte argentino, sobre todo de las provincias de La Rioja, Catamarca, Salta y Jujuy. ${ }^{72}$ La introducción del escrito de Brackebusch reconoció la importancia de ampliar las exploraciones hacia todas las provincias,

67 Ibid.

68 Ibid.

69 Se refiere a las actuales provincias de Río Negro, Neuquén, La Pampa, Santa Cruz, Chubut y Tierra del Fuego.

70 Brackebusch, "Viaje a la Provincia de Jujuy. Discursos pronunciados en el Instituto Geográfico Argentino (Sección Córdoba)", p. 185.

71 Ibid.

72 Ibid. 
pues en un país de tanta extensión aún faltaba conocer científicamente los distintos cuerpos vegetales y su utilidad socioeconómica, sobre todo en provincias con una incierta frontera internacional.

Brackebusch indicó que los miembros de la ANC mostraban "nobles pensamientos" que guiaban la exploración de las provincias argentinas a partir de su formación en Europa, pues mostraban "la fecunda aplicación, el talento, la inteligencia, la bravura y el entusiasmo" como valores indispensables para recorrer los insondables bosques del país. ${ }^{73} \mathrm{La}$ imagen del científico heroico fue común en la época, pues se consideraba un individuo dotado de capacidades distintas al común de los hombres por las características ya señaladas, requeridas para la práctica de las ciencias naturales en parajes comúnmente alejados de las comodidades urbanas.

Eduardo L. Holmberg publicó en 1887 su relato sobre la exploración a Misiones, que incluyó las provincias de Corrientes y Entre Ríos. El escrito inició de la siguiente manera:

— ¡Oh. Un viaje a Europa! ¡París! ¡Oh París!”- He oído decir muchas veces. En efecto, parece que hay allí su tentación.

Pero, ¿podría comparar el placer de estar en París con la angustia de que un viajero o un naturalista me preguntara en la Capital de Francia:

¿Y Misiones? ¿Qué es eso? ¿Qué hay de positivo respecto de esa tierra misteriosa? ${ }^{74}$

El señalamiento del autor sobre el interés del común de los argentinos por viajar hacia las metrópolis culturales fue contrapuesto al desconocimiento de las "tierras misteriosas" del propio país, a las que sólo algunos individuos se aventuraban, en especial el "científico heroico", interesado en develar lo desconocido de la naturaleza desde el punto de vista positivo. El motivo que perseguían hombres como Holmberg radicaba en el "descubrimiento" de especies, paisajes y datos para la ciencia, con los cuales alcanzarían renombre universal, emulando a Darwin, Bonpland, Humboldt y tantos otros, después de su periplo americano.

En 1886 Federico Kurtz publicó el informe de la exploración por las provincias de Córdoba, San Luis y Mendoza y la frontera con Chile. El naturalista explicó que el motivo del periplo había sido "formar una idea sobre la vegetación de las provincias, la cual ha sido bastante desconocida hasta ahora y por consiguiente insuficientemente representada en el herbario de la

73 Brackebusch, "Viaje a la Provincia de Jujuy. Discursos pronunciados en el Instituto Geográfico Argentino (Sección Córdoba)", p. 186.

74 Holmberg, "Viaje a Misiones", p. 19. 
Universidad" ${ }^{75}$ Quince años después del escrito de Lorentz se aprecian semejanzas frente a la necesidad de continuar con los conocimientos botánicos de la Argentina, afianzar las colecciones iniciadas por los académicos en la década de 1870 y seguir con la publicación de los resultados. Esto denota el largo aliento de la práctica botánica y las continuidades de su quehacer en las décadas de 1870 y 1880, un lapso fundacional de la exploración científica a cargo de instituciones nacionales.

Kurtz enfatizó la necesidad de "comparar la flora de la Cordillera" con el interior argentino para precisar la distribución de los grupos taxonómicos y reconocer cuáles eran las regiones botánicas del país. ${ }^{76}$ Una diferencia frente a Lorentz se encuentra en el interés por desarrollar comparaciones entre floras específicas a través de los resultados de las exploraciones naturalistas después de quince años. Una aspiración que tardó tres lustros en ponerse en marcha, gracias a las iniciales recolección de especímenes y sistematización científica llevadas a cabo en el seno de la ANC.

\section{INFORMANTES EN LAS EXPLORACIONES}

El desarrollo y resultado de las exploraciones de los miembros de la ANC hubieran sido distintas sin la interacción de los informantes locales de las regiones que recorrieron, muchos de los cuales son señalados en los escritos publicados en el BANC. Se advierten tres tipos de informantes: los habitantes "iletrados" de la localidad, los letrados locales y los letrados extranjeros residentes. ${ }^{77}$

$\mathrm{Al}$ recorrer la Argentina los académicos mantuvieron la tendencia de sus antecesores dieciochescos, gran parte de ellos miembros de las reales expediciones hispánicas, ${ }^{78}$ además de Alexander von Humboldt, Aimé Bonpland, Charles Darwin, Víctor de Moussy, entre otros, quienes contactaron a los letrados americanos, es decir, "personas con "ojos entrenados" que recolectaban y enviaban especímenes de lugares remotos" hacia las metrópolis

75 Kurtz, "Informe preliminar de un viaje botánico efectuado por orden de la Academia Nacional de Ciencias en Córdoba, en las provincias de Córdoba, San Luis y Mendoza hasta la frontera de Chile, en los meses de diciembre 1885 a Febrero de 1886", p. 349

76 Ibid., p. 350.

77 Se denomina letrado a los individuos que ostentaban alguna profesión científica o humanística o eran aficionados a la ciencia y estaban al tanto de los aspectos teóricos y práctico de una o más disciplinas. En contraposición se encontraba el pueblo, que los letrados consideran en ocasiones supersticioso, ignorante o bárbaro, pero no por ello carente de información útil para los naturalistas.

78 Se refiere a las reales expediciones de Perú y Chile, Río de la Plata, Nueva Granada, Cuba, Nueva España, entre otras. 
europeas para acopiarlos en museos y jardines botánicos. ${ }^{79}$ Durante el siglo XIX los científicos del Viejo Mundo también aprovechaban los conocimientos y las prácticas letradas y populares de las comunidades locales una vez que se encontraban en América, lo cual resultó de gran valor "para comprender algunos hábitos alimenticios, reproductivos y de poblamiento de varias especies". ${ }^{80}$

Al respecto, Georg Hieronymus en "Observaciones sobre la vegetación de la Provincia de Tucumán" señaló que una de las especies que más llamaron su atención fue la planta conocida popularmente como "paja" o "eibe" debido al uso que los pobladores le daban en su vida diaria. Se trató de una especie pampeana empleada como forraje por los nutrientes que aportaba "a copiosas tropas de ganado y caballos en el tiempo del invierno, cuando ya han desaparecido las gramas anuales" ${ }^{81}$ El naturalista también constató que los agricultores y ganaderos solían cubrir sus casas con las macollas del eibe para guardar el calor del hogar, "además el arriero utiliza esa paja en otros sentidos, como v. gr. en caronas de los aparejos, etc." ${ }^{82}$ El contacto de Hieronymus con los hombres de campo de Tucumán aportó elementos importantes para su reconocimiento botánico durante el periplo, pues ellos conocían muchas especies por su contacto cotidiano, además de que le mostraron la utilidad de varias plantas, así como su ubicación e incluso las relaciones existentes con otras especies, por ejemplo, las animales. La información sobre la utilidad social de las especies no se encontraba en la determinación taxonómica, sino en la posible entrevista que Hieronymus tuvo con los pobladores.

Otra planta descrita por Hieronymus fue el cebil (Anadenanthera colubrina), en particular le llamó la atención su cáscara, la cual se empleaba por el pueblo para curtir cueros y el naturalista llegó a recomendar su comercio por todo el país, ya que consideraba a esta especie como el mejor material para ello e incluso animó a los lectores a cultivarla de manera intensiva para exportarla a Europa. Una vez que Hieronymus regresó a Córdoba, solicitó al doctor Max Siewert el análisis químico del cebil y los resultados concluyeron que contenía $10 \%$ de tanino, lo que representaba $4 \%$ más "que el mejor material que se halla en Europa para la misma industria, que es la cáscara del roble (Quercus robur y Q. sessiliflora). ¡Qué riqueza no hay todavía en los cebilares de Tucumán!"” ${ }^{83} \mathrm{La}$ observación del autor permite

79

81 Hieronymus, “Observaciones sobre la vegetación de la Provincia de Tucumán”, p. 198.

82 Ibid.

83 Ibid., p. 323. 
reconocer la metodología seguida con algunas especies hasta entonces desconocidas. Primero se observaban y colectaban plantas en el recorrido para luego preguntar a los pobladores sobre varias de ellas, aunque también hay que señalar que los naturalistas hallaban algunas especies después de su conversación con los habitantes locales. En segundo lugar estaba el trabajo de gabinete en Córdoba, tanto la descripción de cada especie como la ubicación geográfica y en el sistema taxonómico, e incluso el análisis químico cuando se conocían sus usos populares. Después se encontraba la fase de escritura de los resultados y por último, su comunicación en el seno de la ANC para luego publicarse en el BANC. Un camino epistémico común en la época entre los científicos. Si bien gran parte de los datos de la exploración se encuentra en los escritos del $B A N C$, debe tomarse en cuenta que existen omisiones, olvidos y silencios por parte de los académicos. Un tema que requiere una investigación aparte con otras fuentes, por ejemplo, las libretas de viaje.

Hieronymus censuró el aprovechamiento intensivo que los pobladores de Tucumán hacían del cebil, pues se había tratado "desde muchos años de muy mala manera este árbol útil [...] y se expolia ahora todavía en muchas partes de la República Argentina, de una manera bárbara estas selvas excelentes". ${ }^{84}$ En su contacto con los habitantes el naturalista apreció que el estanciero sólo pensaba en "una ganancia momentánea, suele mandar a sus peones a la selva para sacar la cáscara del árbol" y éstos carecían del interés por conservar el recurso silvícola de su dueño, "son demasiado lerdos y cómodos para cortar el árbol y sacarle después toda la cáscara". ${ }^{85}$ Los peones descortezaban el ceibal hasta donde alcanzaban sus manos, "lo pelan en su periferia y se contentan con poder llenar pronto su carro", dañando al árbol al exponerlo a enfermedades y la inclemencia del ambiente, lo que provocaba que el árbol muriera poco tiempo después. ${ }^{86}$

En sus recorridos, Hieronymus observó que "se puede andar a veces leguas enteras en selvas compuestas de cadáveres de árboles de cebil", lo que ofrecía al naturalista un "aspecto triste, que atestigua la imprudencia y la avaricia del hombre, que con la bella naturaleza de estas selvas aniquila su propiedad y la de sus descendientes" ${ }^{87} \mathrm{La}$ censura del autor refleja la distancia intelectual que los académicos transmitieron al público del BANC al señalar, por un lado, la riqueza del conocimiento popular para encontrar plantas útiles y por otro lado, cómo las prácticas de los habitantes eran su-

Ibid. 
puestamente bárbaras, supersticiosas y pedestres, merecedoras de la reprimenda del letrado. Hieronymus se apropió del saber local sobre el cebil para luego denostar el aprovechamiento "irracional" de los tucumanenses al destruir la selva y mermar un recurso natural del país. Sólo la ciencia guiaría a los pobladores para mejorar la explotación del ceibil e incrementar las ganancias.

Hieronymus también indicó que algunos estancieros tucumanos "quieren hacerse razonables. Algunos de los más inteligentes, han notado que con los terrenos cubiertos de selva de cebil se pierde también la fuente de ganancia que podía ser sempiterna", razón por la cual urgía a la ANC a popularizar las pautas científicas para que éstos aprendieran a beneficiarse racionalmente mediante nuevas técnicas sancionadas por la experiencia científica. ${ }^{88}$ Además, el naturalista recomendó a los estancieros aprovechar las hojas bipinnadas del cebil como alimento para el ganado vacuno en el invierno cuando el pasto era escaso. Incluso se recomendó la madera del cebil para elaborar marcos de puerta, filas de arados y otros objetos necesarios en las estancias y pueblos. ${ }^{89}$ Las palabras del académico también indican el contacto con los estancieros "inteligentes", probablemente la élite rural de Tucumán, con la que pudo discutir sobre las pautas de la ciencia útil encaminadas a mejorar la producción silvícola a través del uso racional de varias partes del árbol. Esto fue un elemento constante en las reflexiones finales de los informes de los académicos.

Ludwig Brackebusch señaló que desde el inicio de la exploración sobre la Provincia de Jujuy el gobierno regional lo había recibido "con grande amabilidad, y puso a mi disposición una buena suma de datos que debían servir a mi objeto. No menos amables se mostraron muchas personas distinguidas de aquella sociedad, tanto los hijos del país como compatriotas míos". ${ }^{90}$ Uno de éstos fue el vicecónsul alemán de apellido Ziegener, quien "se distinguía por sus atenciones" para con el naturalista, por ejemplo, lo presentó con los médicos y farmacéuticos locales que podrían orientarlo en su viaje, y proporcionó información sobre la naturaleza local. ${ }^{91}$ Brackebusch también contó con la ayuda de Miguel Francisco Araoz, dueño de la estancia San Pedro y de "una de las más renombradas fábricas de azúcar de la Provincia que ha introducido hermosas maquinarias de Inglaterra, fabrican un producto excelente". ${ }^{92}$ El académico dejó constancia de cómo la élite de

88

89 Ibid., p. 326.

90 Brackebusch, "Viaje a la Provincia de Jujuy. Discursos pronunciados en el Instituto Geográfico Argentino (Sección Córdoba)", p. 193.

91 Ibid.

92 Ibid. 
Jujuy le abrió las puertas para emprender su exploración por la provincia, ya fueran gobernantes, empresarios, compatriotas y profesionistas. Araoz es un representante de los hombres "inteligentes" que destacaban en la economía regional, fueran estancieros, mineros, empresarios o comerciantes, como había señalado Hieronymus, quienes se interesaban en conocer a los académicos y entablar relaciones que posiblemente beneficiaban a ambas partes.

Brackebusch también recibió la orientación de los señores Ovejero del pueblo de Ledesma, poseedores de una fábrica de azúcar "con excelentes maquinarias inglesas". ${ }^{93}$ De igual manera mencionó a la familia Villar, propietaria de la fábrica de azúcar San Lorenzo, en donde se alojó para el estudio de los alrededores del "majestuoso Cerro de Calilegua" y el Valle Grande, caracterizado por "montes maravillosos, la fertilidad del suelo, que produce aquí también un café excelente, como plátanos, etc., es extraordinaria. Aquí se hallará el verdadero jardín de la República, cuando las comunicaciones sean más fáciles" con la construcción del ferrocarril. ${ }^{94}$ Varios empresarios de Jujuy recibieron a Brackebusch en sus propiedades, gracias a lo cual tuvo la capacidad para reconocer la flora provincial y probablemente acopiar información de todo tipo que le permitió elaborar su escrito científico. Si bien se menciona a los dueños de las fábricas, quienes estaban en contacto con la tecnología europea, es de suponer que los trabajadores también aportaron conocimiento e incluso fueron guías en sus periplos, así como mostraron las tradiciones locales sobre el aprovechamiento de la flora.

El argentino Eduardo L. Holmberg en su relato de la exploración al Territorio de Misiones y las provincias de Corrientes y Entre Ríos indicó que después de instalarse en un hotel de la ciudad de Paraná visitó al ministro Miguel Laurencena (1851-1928), a quien lo ligaba una amistad de largos años. El académico recibió de este político varias recomendaciones oficiales dirigidas al general Eduardo Racedo, gobernador, con el propósito de efectuar sus excursiones por diversos puntos de la Provincia de Entre Ríos. ${ }^{95} \mathrm{La}$ red de relaciones de la élite política e intelectual del país fue otra vía en que los académicos recibieron información, recursos y apoyo de todo tipo para cumplir con sus objetivos científicos. Tal vez Laurencena y Racedo no aportaron información científica, pero sí es posible que pusieran en contacto a Holmberg con los letrados locales.

93 Ibid, p. 196.

Ibid., p. 197.

Holmberg, "Viaje a Misiones", p. 22. 
En efecto, gracias a Laurencena el Dr. Holmberg logró entrevistarse con el profesor italiano Pietro Scalabrini (1848-1916), ${ }^{96}$ residente en Paraná, "cuyos interesantes descubrimientos en los depósitos terciarios del Paraná son hoy universalmente apreciados por las personas que se dedican a la Paleontología". ${ }^{97}$ El profesor italiano laboraba en el museo de la ciudad fundado en 1884 y tenía como ayudante a un joven "con excelentes disposiciones para el estudio de los fósiles, y que, si no encuentra obstáculos en su camino, si los triunfos de la investigación y del descubrimiento no le marean", tendría un porvenir en las ciencias, a menos que fuera atrapado "por la tentación diabólica de la política" local o desistiera por el cansancio al comenzar la carrera científica, "seducido por otros brillos, más fastuosos, pero menos duraderos que los que oculta el cerebro". ${ }^{98}$ El académico expresó a sus lectores la importancia de orientar a los jóvenes a la ciencia, como una actividad imprescindible para el futuro nacional, frente a la arena política que había generado discordias desde inicios del siglo. La presencia de científicos extranjeros en varias provincias argentinas adscritos a instituciones académicas revela la dependencia de la ciencia nacional con la europea, como el proyecto fundacional de la ANC, basada en la migración de letrados a la Argentina.

Holmberg valoró las colecciones reunidas por Scalabrini como de gran mérito por la amplia cantidad de nuevos géneros y especies hasta entonces desconocidos. ${ }^{99}$ La consulta a los letrados locales, algunos científicos extranjeros reconocidos en la Argentina, fue parte de la red de relaciones intelectuales que los miembros de la ANC aprovecharon en su periplo cuando tuvieron la ocasión. También se evidencia la visita a los establecimientos científicos provinciales, como el Museo de Paraná, en que se efectuaban prácticas científicas semejantes a las de la ANC, como el acopio y consulta de colecciones, bibliotecas, instrumentos, además del intercambio de experiencias con los científicos locales sobre la región.

El naturalista concluyó el escrito agradeciendo a quienes en diversas ocasiones durante su estancia en Paraná pusieron "colecciones a mi disposición y cuyos nombres, muestran bien claramente el interés que han tomado por esta clase de tarea" científica y aunque el académico omitió tales nombres, "porque temiera olvidar alguno" no dejó pasar su agradecimiento pú-

Scalabrini fue un profesor italiano que emigró a la Argentina. Laboró en escuelas de Corrientes y Entre Ríos. En 1886 en Paraná fundó el museo provincial, en donde desarrolló exploraciones paleontológicas, geológicas y arqueológicas.

97 Holmberg, "Viaje a Misiones", p. 22.

98 Ibid., p. 23.

99 Ibid., p. 25. 
blico. ${ }^{100}$ La ausencia de los nombres de los informantes, salvo las personalidades científicas, políticas y económicas, es constante en los escritos botánicos del $B A N C$, probablemente porque el discurso científico de la época tendía al personalismo y dejaba de lado la construcción grupal del conocimiento científico para mantener el "heroísmo" del autor de cada escrito.

\section{LOS RESULTADOS DE LAS EXPLORACIONES BOTÁNICAS}

Los cinco académicos de la ANC presentes en el artículo dieron a conocer como resultado científico el informe de cada exploración en el $B A N C$, además de la formación de colecciones de plantas, listados taxonómicos de nuevas especies a manera de folletos y cuadros botánicos regionales, la publicación de láminas y mapas botánicos, así como la elaboración de monografías sobre la utilidad de algunas especies. Todos estos resultados posteriores a las expediciones científicas por lo común se intercambiaban con otras instituciones de la Argentina y el mundo, con lo que se propiciaba la circulación del conocimiento especializado. ${ }^{101}$ De igual manera, el gobierno argentino empleaba la información producida por la ANC para impulsar sus proyectos económicos, de colonización, comunicación, transporte y defensa de las fronteras. Así, la ciencia reforzaba las decisiones de los gobernantes tendientes al "progreso" del país. ${ }^{102}$

De acuerdo con el escrito de Hieronymus, los especímenes tucumanenses enriquecieron directamente la colección naturalista de la ANC, la cual se encontraba en su etapa de formación. ${ }^{103}$ Esta colección se complementó con el informe del "largo y extenso viaje científico al norte de la República Argentina" que serviría tanto a los intelectuales como a la sociedad en general para admirar el "bosquejo de la vegetación de la provincia de Tucumán, como su primera contribución para el conocimiento científico de esta República". ${ }^{104}$ En los primeros años de existencia de la ANC los académicos justificaron la publicación del informe de exploraciones como la base para el desarrollo de la ciencia argentina y el primer paso para el acopio de especímenes e información de las regiones menos conocidas del país. También hay que resaltar que con el paso del tiempo los especímenes duplicados fueron

\footnotetext{
100 Ibid., p. 29.

101 Goebel, "Hacia un modelo de análisis histórico de la explotación económica de los bosques en Costa Rica y sus condicionantes institucionales y socioambientales", p. 334.

102 Germani y De Souza, "La apropiación del territorio y el control de los recursos naturales en Brasil", p. 58.

103 Hieronymus, “Continuación. Observaciones sobre la vegetación de la Provincia de Tucumán”, p. 330.

104 Hieronymus, “Observaciones sobre la vegetación de la Provincia de Tucumán”, p. 183.
} 
objeto de canje con otras instituciones argentinas y del extranjero para enriquecer mutuamente los acervos.

En cuanto a la utilidad de algunas especies, el profesor Hieronymus escribió que el lector tendría el primer panorama "de la riqueza de maderas y de vegetales que se hallan aquí. Nos cabe el placer de decir, que no se ha agotado todavía el conocimiento de estas selvas tucumanas" a disposición de los grupos económicos (ganaderos, agricultores, mineros, comerciantes, artesanos, industriales, entre otros). ${ }^{105}$ La Botánica fue una ciencia útil en el reconocimiento de los recursos naturales que las naciones latinoamericanas requerían para consolidar el devenir del Estado nacional, así como una disciplina que aportaba evidencias científicas para atraer colonos y capitales interesados en desarrollar a gran escala la agricultura, la silvicultura, el artesanado, la industria y el comercio.

Hieronymus expresó sobre la vegetación tucumanense que había iniciado la clasificación de los especímenes y esperaba a más tardar en un año presentar al gobierno argentino "otro informe que dará por lo menos una parte de dichos resultados". ${ }^{106}$ Las conclusiones de esta exploración botánica se centraron en lo valioso de dar los primeros pasos en el reconocimiento científico, lo escaso de su examen sistematizado anterior a la década de 1870 y la necesidad de que el gobierno apoyara a la ANC para aumentar sus capacidades de apropiación del territorio y la naturaleza de la Argentina para luego comunicar los resultados al mundo científico internacional.

Sobre Paul Lorentz, el relato de las exploraciones de 1870 a 1872 mostró que los resultados científicos más importantes eran los siguientes: primero, la complicada clasificación de todas las plantas coleccionadas, pues el naturalista en "un país inexplorado encuentra las mayores dificultades, y sólo puede hacerlo aprovechando los recursos científicos" que tiene a su alcance para comparar la flora argentina con la de países vecinos, que también eran "poco conocidas en muchas partes, el Brasil, Bolivia y Chile". ${ }^{107}$ Esto complicaba la labor de comparación taxonómica. Ante esta situación, Lorentz consultó obras extranjeras, "algunas muy costosas", que contenían varias familias, géneros y especies similares a la flora argentina con las cuales se facilitaba la determinación de nuevas especies. También se carecía de un herbario nacional, por lo que el autor recomendó al gobierno apoyar la formación de una colección botánica que contuviera especies de todas las pro-

105 Hieronymus, “Continuación. Observaciones sobre la vegetación de la Provincia de Tucumán”, p. 423.

106 Ibid., p. 422.

107 Lorentz, "Informe científico sobre el resultado de los viajes y excursiones botánicas hechas desde el mes de noviembre de 1870 hasta el mismo mes de 1872", p. 97. 
vincias y bajo resguardo de la ANC. Con éste se estudiaría la vegetación del país, pues "sin los nombres técnicos, es un trabajo ímprobo, porque la nomenclatura científica es la única lengua que se entiende en todo el mundo". ${ }^{108}$ El proceso de descripción que emprendieron los académicos en la década de 1870 sólo fue posible gracias a las exploraciones científicas y los resultados que se presentaron públicamente para fundar las bases de la Botánica nacional. En los siguientes años estos botánicos y otros afianzarían el proceso de institucionalización de las ciencias naturales en el país.

Lorentz anunció la próxima publicación del libro La Vegetación de la República Argentina, destinado a presentarse en el pabellón nacional en la Exposición Internacional de Filadelfia de 1876. Esta obra mostraría por primera vez el cuadro estadístico de la vegetación de la Argentina, con énfasis en las plantas útiles de cada familia. ${ }^{109}$ Los fundamentos para el estudio de la flora argentina fueron aportados por Lorentz al sistematizar la información y los especímenes colectados en sus viajes botánicos que no sólo se publicaron en el $B A N C$, sino también se sumaron a los preparativos de la Comisión de Exposición para presentar a la nación argentina en Filadelfia.

Georg Hieronymus reconoció el valor de la colección botánica conformada por Lorentz, cuyas determinaciones científicas correspondían en gran medida al doctor August Grisebach (1814-1879) de la Universidad de Goettingen. ${ }^{110}$ El estudio pormenorizado fue dado a conocer por Grisebach bajo el título de Plantae Lorentzianae (1874) en que se clasificaron 927 nuevas plantas vasculares argentinas. ${ }^{111}$ Esto muestra cómo algunos de los académicos extranjeros mantuvieron estrechas relaciones con sus colegas en el Viejo Mundo, a quienes enviaron materiales científicos inéditos que también enriquecieron a las instituciones alemanas e incluso esto contribuyó a la descripción de ejemplares tipo ${ }^{112}$ fuera de la Argentina. Una cuestión que incrementó la dependencia de la ciencia del país frente a la europea, en particular con la alemana.

Ludwig Brackebusch sobre su exploración a la provincia de Jujuy señaló que había redactado un informe destinado tanto a la ANC como al ministro del Interior para dar a conocer su experiencia y el plan para sistematizar la

\footnotetext{
108 Ibid.

109 Ibid., p. 100.

110 Hieronymus, “Observaciones sobre la vegetación de la Provincia de Tucumán”, p. 183

111 Ortiz, "Las relaciones científicas entre las universidades de Córdoba y Göttingen (18601870): Wappäus, Cáceres y los Seis de Córdoba”, p. 308.

112 Un ejemplar tipo es denominado de esta manera cuando a partir de sus características se definió la especie y estableció las subsecuentes descripciones de nuevos ejemplares.
} 
información obtenida. ${ }^{113}$ De manera similar, Eduardo L. Holmberg al concluir la exploración a Misiones indicó que "bajo la presión del plazo que me había marcado [...] pude entregarme al estudio y preparación de los materiales reunidos, estudio que ahora incluyo en este informe general" que presentó a sus colegas de la ANC. ${ }^{114}$ Ambos académicos muestran la importancia de elaborar y comunicar el informe general de su exploración científica para contribuir al conocimiento de ambas provincias, comprobar la eficacia de los apoyos gubernamentales a los académicos e incluso como un relato que atrajera la mirada de la opinión pública sobre la importancia de la Botánica en el "progreso" del país en cuanto al desarrollo económico y la colonización.

Fritz Kurtz en el informe de la exploración a las provincias de Córdoba, San Luis y Mendoza señaló que uno de los resultados más importantes era la conformación de un herbario de más de 900 especies representadas por 4,500 ejemplares y una colección entomológica de 150 especies. ${ }^{115} \mathrm{El}$ coleccionismo fue el principal resultado material de las exploraciones de la ANC y base para la determinación de especies, la comparación entre floras, el intercambio entre colecciones de varias partes del mundo y la visualización de la flora argentina. En la década de 1880 la ANC se encontraba en un proceso de madurez institucional como se refleja en las capacidades para ampliar las colecciones naturalistas.

Kurtz indicó que gracias a la colección había determinado las siguientes regiones botánicas:

$1^{\circ}$ La vegetación de la sierra Achala, región del Cerro Champaquí.

$2^{\circ}$ La vegetación del valle entre la Sierra de Córdoba y la de San Luis.

$3^{\circ}$ La vegetación de la Sierra de San Luis.

$4^{\circ}$ La vegetación del pie occidental de la Sierra de San Luis (entre San Francisco y San Luis).

$5^{\circ}$ La vegetación de los alrededores de la Laguna Bebedero.

$6^{\circ}$ La vegetación del campo entre San Luis y la cuesta oriental de la Cordillera cerca de Mendoza.

$7^{\circ}$ La vegetación de la Cordillera entre Villavicencio, Uspallata, Puente del Inca y Juncal en Chile. ${ }^{116}$

113 Brackebusch, "Viaje a la Provincia de Jujuy. Discursos pronunciados en el Instituto Geográfico Argentino (Sección Córdoba)", p. 188.

114 Holmberg, "Viaje a Misiones", p. 37.

115 Kurtz, "Informe preliminar de un viaje botánico efectuado por orden de la Academia Nacional de Ciencias en Córdoba, en las provincias de Córdoba, San Luis y Mendoza hasta la frontera de Chile, en los meses de diciembre 1885 a Febrero de 1886", p. 350.

116 Ibíd. 
Los resultados de la exploración de 1886 reflejan una situación distinta a la década anterior, pues Kurtz pudo establecer diferencias fitogeográficas en las provincias argentinas y comparar los especímenes por él colectados frente a sus antecesores. Esta tarea continuaría el resto de la centuria ampliando las capacidades de la ANC para la prospección de la flora de la Argentina.

\section{CONSIDERACIONES FINALES}

La historiografía de la ciencia argentina ha pasado por alto el desarrollo de las disciplinas en el seno de la ANC en el siglo XIX, pues sólo se cuenta con estudios sobre su vida institucional o sobre las labores de algunos de sus académicos de forma individual, enfatizando las complicaciones institucionales, políticas y económicas, y dejando de lado la actividad científica realizada en medio de éstas. No obstante, es necesario investigar a esta corporación desde el conjunto de expediciones organizadas por la ANC en sus primeros quince años de vida institucional y cómo los académicos se interesaron en afianzar la Botánica como una ciencia útil a la Argentina.

El BANC como fuente histórica de la Botánica argentina muestra los relatos de las exploraciones como expresión pública de las actividades de los académicos y cómo cumplían sus compromisos científicos. Los primeros quince años de la publicación son un reflejo de la etapa fundacional de la ANC y su papel modernizador de la ciencia argentina en el marco de la política de apropiación de los recursos naturales por parte del Estado nacional. En la actualidad la historia de la ciencia argentina requiere "explorar con más cuidado ciertos lugares comunes sobre la alianza entre 'ciencia', 'el poder' y 'el control estatal"' en que se ha enfatizado la discontinuidad, el fracaso, las complicaciones, las dificultades y la desorganización del desarrollo de las instituciones. ${ }^{117}$

Los académicos de la ANC gozaron de la ayuda gubernamental para efectuar reconocimientos sistematizados del territorio y la naturaleza de varias regiones argentinas. La investigación botánica al final del siglo XIX se vinculó con la política científica de la Argentina como una ciencia capaz de inventariar los recursos naturales para ampliar los rubros productivos, al igual que propiciar la colonización al exponer los recursos naturales a la espera de individuos capaces de aprovechar la flora útil del país. En los escritos del $B A N C$ se dejó constancia de algunos de los participantes de las exploraciones e incluso de su metodología científica. La observación, la colecta, la

117 Podgorny y Lopes, El desierto en una vitrina. Museos e historia natural en la Argentina, $1810-1890$, p. 253. 
descripción, entre otras actividades, fueron la base con la cual se examinó la flora argentina por parte de los miembros de la ANC mediante el método científico común en el Viejo Mundo. El traslado de la ciencia europea a la Argentina afianzó la dependencia teórica y metodológica que se mantuvo en la siguiente centuria.

El estado argentino tenía la necesidad de exploraciones científicas con las cuales reconocer, controlar y aprovechar el territorio de un extenso país que tenía problemáticas limítrofes internacionales, pero también provinciales. Para ellos, los gobiernos del último tercio de la centuria fundaron y apoyaron a instituciones científicas que cumplieran con la solución a dichas problemáticas. La ANC fue una de estas instituciones que mediante la incorporación de científicos europeos y argentinos puso en marcha un proyecto de exploración de gran alcance, en que la Botánica tuvo un papel fundamental. Los informantes fueron agentes de conocimiento sobre la naturaleza argentina a los que recurrieron los académicos, ya fueran individuos letrados o iletrados, con los cuales se ampliaron los resultados de las exploraciones. La convivencia de los naturalistas con los informantes aportó información que la mera observación de la naturaleza no podría evidenciar, por ejemplo, los usos cotidianos de la flora, pues el reconocimiento de la utilidad económica de las especies fue parte de los objetivos de los académicos.

La formación de colecciones naturalistas en el seno de la ANC fue una práctica científica indispensable para el análisis e inventario de los recursos naturales argentinos, pues antes de 1870 se carecía de acervos públicos consolidados y que representaran la mayor parte del país. A esta tarea se sumaron varios académicos mediante la exploración científica del territorio en cuestiones botánicas, zoológicas, paleontológicas, minerales, antropológicas, arqueológicas, entre otros rubros.

Dentro de la política científica de los sucesivos gobiernos argentinos se mantuvo el interés por la prospección de la flora de las distintas regiones como un recurso útil para la economía nacional. Para ello se requerían de estudios especializados que tradujeron en gran parte el saber popular que los académicos observaron y examinaron hacia propuestas que señalaran cómo aprovechar varias especies nativas e, incluso, aclimatar otras.

Los resultados científicos de los académicos se concentraron en el acopio de especímenes en el museo de la ANC, la publicación de los informes de las exploraciones y la elaboración de otros materiales, por ejemplo, cuadros, tablas, folletos y libros derivados de los informes generales. En casi quince años la ANC produjo varios materiales que contribuyeron a ampliar la literatura científica publicada en la Argentina, así como se intercambió con instancias extranjeras para dar a conocer el desempeño académico nacional.

Las expediciones botánicas organizadas por la ANC después de 1887 continuaron los propósitos de las aquí analizadas, aunque contaron con una 
base material distinta, pues ya se tenían colecciones, informes, obras publicadas, además de la experiencia institucional, así como la mejora en la comunicación y los transportes en gran parte del país, y las ligas intelectuales que se tenían con varios centros científicos del mundo. Otras publicaciones científicas que incluyen temas botánicos son Anales de la Sociedad Cientifica Argentina, Anales del Círculo Médico Argentino, Anales del Museo de Buenos Aires, Revista de la Sociedad Geográfica Argentina, El Naturalista Argentino, Apuntes de Historia Natural, Boletín del Instituto Geográfico Argentino y Anales de la Revista del Museo de La Plata. Todas estas publicaciones requieren otras investigaciones en el ámbito de la historia de la Botánica argentina.

Por último, se requieren nuevas investigaciones que, por un lado, confronten los estudios botánicos del $B A N C$ con la documentación archivística, las colecciones y la producción bibliográfica de la ANC, así como con otras publicaciones botánicas de la época; y por otro, examinar tanto la recepción de los informes y las colecciones resultado de las exploraciones botánicas como los ejemplos de utilidad concreta en las actividades económicas.

\section{BiBLIOGRAFÍA}

Anónimo, "Reglamento de la Academia Nacional de Ciencias", Boletín de la Academia Nacional de Ciencias, vol. III, 1879, pp. 3-10.

Azuela, Luz Fernanda, "La institucionalización de las ciencias en México durante el porfiriato", en María Luisa Rodríguez-Sala y Iris Guevara (coords.), Tres etapas del desarrollo de la cultura científico-tecnológica en México, México, Universidad Nacional Autónoma de México, 1996, pp. 73-84.

Azuela, Luz Fernanda y Rodrigo Vega y Ortega, "La Academia Imperial de Ciencias y Literatura de México, 1865-1866", en Luz Fernanda Azuela y Rodrigo Vega y Ortega (coords.), Actores y espacios de la Geografia y la Historia Natural de México, siglos XVIII-XX, México, Universidad Nacional Autónoma de México, 2015, pp. 55-82.

Babini, José, Historia de la ciencia en la Argentina, Buenos Aires, Ediciones Solar, 1986.

Becerra, Diego y Olga Restrepo, "Las ciencias en Colombia: 1783-1990. Una perspectiva histórico-sociológica", Revista Colombiana de Educación, núm. 26, 1993, pp. 30-58.

Brackebusch, Ludwig, "Viaje a la Provincia de Jujuy. Discursos pronunciados en el Instituto Geográfico Argentino (Sección Córdoba)", Boletín de la Academia Nacional de Ciencias, vol. V, 1883, pp. 185-252.

Bruno, Paula, "Eduardo L. Holmberg en la escena científica argentina. Ideas y acciones entre la década de 1870 y el fin-de-siglo", Saber y Tiempo, vol. I, núm. 1, 2015, pp. 118-140. 
Burmeister, Germán, "Crónica de la Academia de Ciencias Exactas durante el año de 1874, por el Director de la misma", Boletín de la Academia Nacional de Ciencias, vol. I, 1874, pp. 503-508.

, "Reseña histórica sobre la fundación y progresos de la Academia de Ciencias Exactas en Córdoba, por el director científico de la misma", Boletín de la Academia Nacional de Ciencias, vol. I, 1874, pp. 1-3.

Capel, Horacio, "El asociacionismo científico en Iberoamérica. La necesidad de un enfoque globalizador", en Antonio Lafuente, Alberto Elena y María Luis (ed.), Mundialización de la ciencia y cultura nacional, Madrid, Universidad Autónoma de Madrid/Doce Calles, 1993, pp. 409-428.

Carreras, Sandra, "Unas carrera científica entre Prusia y Argentina: el itinerario de Hermann Burmeister", Iberoamericana, vol. IX, núm. 33, 2009, pp. 89-101.

Curto, Susana, Graciela Jáuregui, Mónica Escuela, Marcelo Lascano y Héctor Pena, "La fundación de GÆA Sociedad Argentina de Estudios Geográficos-1922", Boletín de GEA, núm. 126, 2008, pp. 1-49.

Depetris, Pedro José, “Charles Robert Darwin and Argentina's National Academy of Sciences”, Revista de la Asociación Geológica Argentina, vol. LXIV, núm. 1, 2009, pp. 8-129.

Di Liscia, María, “La cornucopia del 'desierto'. Expediciones, científicos y recursos vegetales en la Pampa del siglo XIX y primera mitad del XX”, Saber y Tiempo, vol. VI, núm. 21, 2006, pp. 25-41.

Di Pasquale, Mariano, "Entre la experimentación política y la circulación de saberes: la gestión de Bernardino Rivadavia en Buenos Aires, 1821-1827”, Secuencia, núm. 87, 2013, pp. 61-65.

Farro, Máximo E., "Redes y medios de transporte en el desarrollo de expediciones científicas en Argentina (1850-1910)", História, Ciências, SaúdeManguinhos, vol. XV, núm. 3, 2008, pp. 679-696.

García Castellanos, Telasco, Breve historia de la Academia Nacional de Ciencias de Córdoba, República Argentina, Córdoba, Academia Nacional de Ciencias, 1987.

Germani, Guimoar y Luiz Antonio de Souza, "La apropiación del territorio y el control de los recursos naturales en Brasil", en Eulalia Ribera, Héctor Mendoza y Pere Sunyer (coord.), La integración del territorio en una idea de Estado, México y Brasil, 1821-1946, México, Universidad Nacional Autónoma de México-Instituto de Investigaciones Dr. José María Luis Mora, 2007, pp. 5857-5878.

Goebel, Anthony, "Hacia un modelo de análisis histórico de la explotación económica de los bosques en Costa Rica y sus condicionantes institucionales y socioambientales", en Celina Lértora (coord.), Geografía e historia natural: hacia una historia comparada. Estudios a través de Argentina, México, Costa Rica y Paraguay, Buenos Aires, Fundación para el Estudio del Pensamiento Argentino e Iberoamericano, 2009, pp. 307-346. 
González Bernaldo de Quirós, Pilar, “Sociabilidad y opinión pública en Buenos Aires (1821-1852)”, Historia Contemporánea, núm. 27, 2003, pp. 663-694.

Hahn, Roger, The Anatomy of a Scientific Institution. The Paris Academy of Sciences, 1666-1803, Berkeley, University of California Press, 1971.

Hieronymus, Georg, "Continuación. Observaciones sobre la vegetación de la Provincia de Tucumán”, Boletín de la Academia Nacional de Ciencias, vol. I, 1874, pp. 299-423.

__ "Observaciones sobre la vegetación de la Provincia de Tucumán”, Boletín de la Academia Nacional de Ciencias, vol. I, 1874, pp. 183-234.

Holmberg, Eduardo L., "Viaje a Misiones", Boletín de la Academia Nacional de Ciencias, vol. X, 1887, pp. 19-43.

Jardine, Nicholas y Emma Spary, "The natures of cultural history”, en Nick Jardine, James Secord y Emma Spary (ed.), Cultures of Natural History, Cambridge, Cambridge University Press, 1996, pp. 7-22.

Josa, Jaume, "La Historia Natural en la España del siglo XIX: Botánica y Zoología", Ayer, núm. 7, 1992, pp. 109-152.

Kurtz, Fritz, "Informe preliminar de un viaje botánico efectuado por orden de la Academia Nacional de Ciencias en Córdoba, en las provincias de Córdoba, San Luis y Mendoza hasta la frontera de Chile, en los meses de diciembre 1885 a febrero de 1886", Boletín de la Academia Nacional de Ciencias, vol. IX, 1886, pp. 349-370.

López Ocón, Leoncio, "La formación de un espacio público para la ciencia en la América Latina durante el siglo XIX”, Asclepio, vol. L, núm. 2, 1998, pp. 205-225.

Lorentz, Paul G., "Informe científico sobre el resultado de los viajes y excursiones botánicas hechas desde el mes de noviembre de 1870 hasta el mismo mes de 1872", Boletín de la Academia Nacional de Ciencias, vol. I, 1875, pp. 90125.

Lorenzano, César, Por los caminos de Leloir. Estructura y desarrollo de una investigación Nobel, Buenos Aires, Biblios, 1994.

Mantegari, Cristina, Germán Burmeister. La institucionalización científica en la Argentina del siglo XIX, Buenos Aires, Universidad Nacional de San Martín, 2003.

Massarani, Luisa y Ildeu de Castro Moreira, "Popularisation of Science: Historical Perspectives and Permanent Dilemmas", Quark, núm. 32, 2004, pp. 75-79.

Montserrat, Marcelo, Ciencia, historia y sociedad en la Argentina del siglo XIX, Buenos Aires, Centro Editor de América Latina, 1993.

Nisbet, Robert A., Historia de la idea de progreso, Barcelona, Gedisa, 1981.

Ortiz, Eduardo L., "Las relaciones científicas entre las universidades de Córdoba y Göttingen (1860-1870): Wappäus, Cáceres y los Seis de Córdoba”, en Daniel Saur y Alicia Servetto (coord.), Universidad Nacional de Córdoba. Cuatro- 
cientos años de historia, Córdoba, Universidad Nacional de Córdoba, 2013, pp. 283-324.

Peralta, Jaime, "De 'delirios ignorantes'a 'cultas reflexiones': la Ilustración europea y la apropiación de los saberes de la periferia colonial", Fronteras de la Historia, vol. XIX, núm. 1, 2014, pp. 72-95.

Pickstone, John V., Ways of knowing. A new history of science, technology and medicine, Manchester, Manchester University Press, 2000.

Podgorny, Irina y María Margaret Lopes, El desierto en una vitrina. Museos e historia natural en la Argentina, 1810-1890, México, Limusa, 2008.

Polo, Jorge, "Colonialidad del poder y violencia epistémica en América Latina", Revista Latina de Sociología, vol. VI, 2016, pp. 27-44.

Pratt, Mary Louise, Ojos imperiales. Literatura de viaje y transculturación, México, Fondo de Cultura Económica, 2010.

Pruna, Pedro, La Real Academia de Ciencias de La Habana 1861-1898, Madrid, Consejo Superior de Investigaciones Científicas, 2002.

Ramos, Víctor A., "Doscientos años de Ciencias de la Tierra en la Argentina", Revista de la Asociación Geológica Argentina, vol. LXVIII, núm. 3, 2011, pp. 392-406.

Saur, Daniel y Alicia Servetto (coords.), Universidad Nacional de Córdoba. Cuatrocientos años de historia, Córdoba, Universidad Nacional de Córdoba, 2013, 2 vols.

Spary, Emma, "Of Nutmegs and Botanists. The Colonial Cultivation of Botanical Identity", en Londa Schiebinger y Claudia Swan (ed.), Colonial Botany. Science, Commerce, and Politics in the Early Modern World, Philadelphia, University of Pennsylvania Press, 2005, pp. 187-200.

Tognetti, Luis, “¿Catedrales de las ciencias o templos del saber? Los museos de ciencias naturales de Córdoba, Argentina, a fines del siglo XIX”, História, Ciências, Saúde-Manguinhos, vol. VIII, núm. 1, 2001, pp. 35-47.

Tognetti, Luis y Carlos Page, La Academia Nacional de Ciencias. Etapa Fundacional-Siglo XIX, Córdoba, Academia Nacional de Ciencias, 2000.

Vera, Maria Cristina, "Notas para la historia de la universidad en Argentina", Revista Historia de la Educación Latinoamericana, núm. 8, 2006, pp. 65-112.

Vizcaíno, Sergio, Susana Bargo y Juan C. Fernicola, "Expediciones paleontológicas durante los siglos XIX y XX a la Formación Santa Cruz (Mioceno inferior, Patagonia) y destino de los fósiles", en Ricardo Alonso (ed.), III Congreso Argentino de Historia de la Geología, Salta, Sociedad Geológica Argentina, 2013, pp. 231-246. 